\author{
Original Article
}

\title{
Effects of High-Energy Curing Lights on Time-Dependent Temperature Changes of Pulp Space During Orthodontic Bonding
}

\author{
Nisa Gül Amuk' (DD, Gökmen Kurt² (D), Özgür Er (D), Gülşen Çakmak ${ }^{4}$ (D), Veysel Aslantaş5 (DD
}

\author{
'Department of Orthodontics, Erciyes University School of Dentistry, Kayseri, Turkey \\ 2Department of Orthodontics, Bezmialem Vakif University School of Dentistry, İstanbul, Turkey \\ ${ }^{3}$ Department of Endodontics, Trakya University School of Dentistry, Edirne, Turkey \\ ${ }^{4}$ Private Practice, Kayseri, Turkey \\ ${ }^{5}$ Department of Computer Engineering, Erciyes University School of Engineering, Kayseri, Turkey
}

Cite this article as: Gül Amuk N, Kurt G, Er Ö, Çakmak G, Aslantaş V. Effects of High-Energy Curing Lights on Time-Dependent Temperature Changes of Pulp Space During Orthodontic Bonding. Turk J Orthod 2019; 32(1): 22-7.

\begin{abstract}
Objective: The purpose of this study was to assess the temperature changes and cooling times during orthodontic bonding by a light-emitting diode (LED) and plasma arc lights (PAC) in different time and power modes with thermal imaging.

Methods: A total of 100 human permanent upper first premolar teeth were included in the study. Five groups were conducted, 20 teeth each, and different energy outputs of curing lights were used for adhesive polymerization with different exposure times. The temperature changes in the pulp space and cooldown times were measured by a thermal imaging system. A paired t-test, analysis of variance (ANOVA), and Student-Newman-Keuls multiple comparison tests were used for data analysis.

Results: A statistically significant temperature rise was detected with all curing lights $(p<0.05)$. The greatest temperature changes were observed in the LED standard mode with 10 seconds of exposure time $\left(6.66 \pm 1.98^{\circ} \mathrm{C}\right)$ and LED extra power mode with 6 seconds of exposure time $\left(6.50 \pm 1.64^{\circ} \mathrm{C}\right)$ among groups, while using PAC for 3 seconds created the smallest temperature increase $\left(1.81 \pm 0.99^{\circ} \mathrm{C}\right)$. An application of the LED extra power mode for 6 seconds exhibited the longest cooldown time (205.91 \pm 47.48 seconds), and the shortest cooldown time was detected as $71.30 \pm 43.15$ seconds with the PAC 3-second application.

Conclusions: LED lights with an increased exposure time induced significant temperature rises, while no PAC light group exceeded the critical threshold value. The exposure time is more important than the energy output level of the light-curing system on temperature increments of the pulp chamber.
\end{abstract}

Keywords: Orthodontic bonding, dental curing lights, thermal imaging, pulp chamber, temperature change

\section{INTRODUCTION}

Light-cured adhesives have become more popular than self-curing resins in recent years for orthodontic bonding because they provide an increased bracket placement and positioning time (1), greater bond strength (1), and easier removal of excess material for some adhesives, also reducing the risk of contamination (2). Various types of curing-light units have been used for orthodontic purposes, such as Quartz tungsten halogen (QTH), light-emitting diode (LED), and plasma arc lights (PAC). The QTH lights have disadvantages, such as a prolonged radiation time and heat generation, and limited lifetime (3). PAC lights, and in particular LEDs, have recently gained popularity because of their shortened curing times.

The intra-pulpal temperature increase has been reported in the literature during composite resin polymerization for different light-curing units $(2,4-6)$. As the result of the study by Zach and Cohen who investigated the effects of temperature rise on the pulp tissue of primates (7), a $5.5^{\circ} \mathrm{C}$ temperature increase in the pulp was found to

Address for Correspondence: Nisa Gül Amuk, Department of Orthodontics, Erciyes University School of Dentistry, Received: March 16, 2018 Kayseri, Turkey 
Table 1. Power intensity, wavelength, and exposure times of light sources provided by the manufacturer

\begin{tabular}{|llllll|}
\hline Groups & $\mathbf{n}$ & Definition & Power Intensity $\mathbf{( m W / \mathbf { c m } ^ { 2 } )}$ & Wavelength $(\mathbf{n m})$ & Exposure Time $(\mathbf{s})$ \\
\hline Group I & 20 & LED standard mode & $1000 \mathrm{~mW} / \mathrm{cm}^{2}$ & $390-480 \mathrm{~nm}$ & 10 \\
Group II & 20 & LED extra power mode & $3200 \mathrm{~mW} / \mathrm{cm}^{2}$ & $390-480 \mathrm{~nm}$ & 3 \\
Group III & 20 & LED extra power mode & $3200 \mathrm{~mW} / \mathrm{cm}^{2}$ & $390-480 \mathrm{~nm}$ & 6 \\
Group IV & 20 & PAC & $1200-1500 \mathrm{~mW} / \mathrm{cm}^{2}$ & $415-520 \mathrm{~nm}$ & 3 \\
Group V & 20 & PAC & $1200-1500 \mathrm{~mW} / \mathrm{cm}^{2}$ & $415-520 \mathrm{~nm}$ & 6 \\
\hline LED: light-emitting diode; PAC: plasma arc curing & & &
\end{tabular}

be the reason of irreversible pulp damage in 15\% of the experimental animals. So, these $5.5^{\circ} \mathrm{C}$ of the intra-pulpal temperature increase were accepted as the threshold value for the irreversible pulp chamber damage in the literature (8).

Studies evaluating the effects of curing lights on temperature increase in the pulp chamber during bracket $(1,2)$ and buccal tube bonding (9) showed that no light source except QTH with high-light intensity (HQTH) (1) exceeded the critical value of $5.5^{\circ} \mathrm{C}$. These studies used various types of thermocouple wires to measure the intra-pulpal temperature rise.

The temperature changes at the entire pulp space during bracket bonding can be also measured with optical thermal imaging systems. This system provides a gradual measurement of temperature changes on the whole pulp area for every second. A major advantage of thermal imaging during light curing is to give information about the cooling time of the pulp space to initial temperature values. Although several studies have evaluated the thermal effects of different curing lights $(1,2,9)$, there was no study that revealed the time-dependent temperature changes in the pulp space, and no study existed that conducted the thermal measurements with thermal imaging during orthodontic bonding. Hereby, the purpose of this study was to assess the time-dependent temperature changes during bracket bonding by two recently popular high-energy light sources, LED and PAC, in the different time and power modes with thermal imaging

\section{METHODS}

The study was approved by the Ethics Committee of Erciyes University (approval number: 2017/472). The informed consent forms were signed by the patients or their legal guardians. The sample size was determined using a statistical power analysis (G*Power Ver 3.1.9.2, Universität Kiel, Germany), which revealed that 20 specimens in each group would give more than $90 \%$ power to detect significant differences ( $a$ error $=0.05$ ).

A total of non-carious, freshly extracted upper first premolar teeth with intact enamel (no cracks, hypoplastic areas, caries, restorations, or irregularities) were selected. Size, shape, and pulp space dimensions of teeth were examined on digital periapical radiographs using the grid superimposition method with image editing and graphic designing software (Adobe Photoshop CS3, Adobe Systems Inc, San Francisco, CA). According to the results of the radiographic assessment, teeth with abnormally shaped and/or sized pulp chambers were excluded from the study, and excluded teeth were replaced with others that did match the inclusion criteria.

The teeth were kept in thymol solution $(0.1 \%)$ which was refreshed weekly for inhibition of microorganism growth. The teeth were sectioned into two halves (buccal and palatal) along the long axis. Remnant pulpal tissues were removed from the pulp cavity using a spoon excavator and $\mathrm{NaOCl}$ solution. Each buccal half of the tooth was embedded in acrylic resin while exposing 2-3 $\mathrm{mm}$ of the root from the cementoenamel junction and the crown. The buccal surfaces of the teeth were polished with non-fluoridated pumice and cleaned with water.

\section{Bonding Procedure}

Each tooth was etched with 37\% phosphoric acid gel (Prime Dental Products, Chicago, Illinois, USA) for 30 seconds, rinsed for 30 seconds, and dried until the frosty white etched area was observed. Sealant (Transbond XT light cure adhesive primer, 3M Unitek, Monrovia, Calif., USA) was applied on the etched enamel and cured for 10 seconds with LED light (standard mode: 1000 $\mathrm{mW} / \mathrm{cm}^{2}, 390-480 \mathrm{~nm}$, Valo ortho cordless curing light, South Jordan, USA). Subsequently, stainless steel brackets (American Orthodontics, 0.018 Roth Mini/Master Series, Sheboygan, USA) with Transbond XT adhesive composite (3M Unitek, Monrovia, Calif., USA) on the mesh base were fully seated into position using an intraoral gage to deliver a standardized force of $250 \mathrm{cN}$ for 5 seconds.

\section{Curing Procedure}

Two different light resources, LED light (Valo ortho cordless curing light, South Jordan, USA) and plasma arc light (American Dental Technologies, Inc., San Carlos, California, USA), with various power and exposure times were investigated in this study (Table 1).

Group I: Twenty samples were cured with the LED light source (Valo ortho cordless curing light, South Jordan, USA) at the standard mode (SM), which has the power intensity of $1000 \mathrm{~mW} / \mathrm{cm}^{2}$ and a wavelength of 390-480 $\mathrm{nm}$ for 10 seconds.

Group II: Twenty samples were exposed to the same LED light source at the extra power mode (EPM), which has the power intensity of $3200 \mathrm{~mW} / \mathrm{cm}^{2}$ and a wavelength of $390-480 \mathrm{~nm}$ for 3 seconds.

Group III: Twenty samples were exposed to the same LED-EPM light (the power intensity of $3200 \mathrm{~mW} / \mathrm{cm}^{2}$ and a wavelength of $390-480 \mathrm{~nm}$ ) for 6 seconds. 


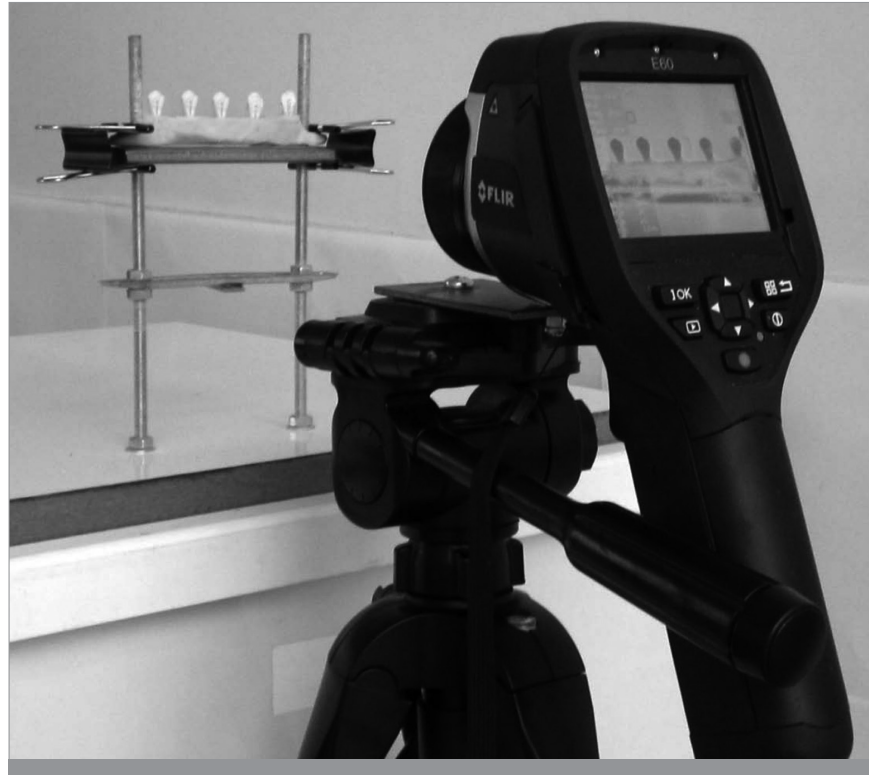

Figure 1. Thermal imaging of sample teeth from a $15 \mathrm{~cm}$ distance

Group IV: A PAC light source (American Dental Technologies, Inc., San Carlos, California, USA), which has the power intensity of 1200-1500 mW/cm² and a wavelength of 415-520 nm, was used for curing of 20 samples for 3 seconds.

Group V: The same PAC light source applied in Group IV was applied on 20 samples for 6 seconds.

The light outputs of the LED curing units were checked before the use by the manufacturer. The distance of the light-guiding tip to brackets was kept at the closest distance for all specimens, and the tip was angulated 90 degrees to the bracket on each tooth. So, the light beam direction was adjusted perpendicularly to the bracket surface.

\section{Thermal Measurement}

The temperature changes during and after bonding were recorded with a FLIR E60 thermal imaging camera (Extech Instruments Corporation, Waltham, MA) and its own software. The resolution of the camera was $320 \times 240$ pixels, and the field of view was $25^{\circ} \times 19^{\circ}$. The camera was located $15 \mathrm{~cm}$ away from the sample blocks, which were fixed with handles (Figure 1) for the standardization of the thermal measurements and recordings.

The experiment was carried out in a special room with controlled

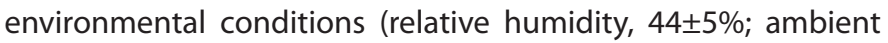
temperature, $26 \pm 0.9^{\circ} \mathrm{C}$; air flow, $<0.5 \mathrm{~m} / \mathrm{s}$ ). Although the same distance between the camera and specimens was calibrated before all measurements, the focus of objective was checked manually for the best image. The temperature window was adjusted to $20^{\circ} \mathrm{C}$ minimally and $40^{\circ} \mathrm{C}$ maximally (Figure 2 ).

Recording was started 2 seconds before polymerization. Changes in the temperature of the pulp chamber during bonding and the duration for returning of the highest temperature values to the initial degrees were recorded, for all specimens. Temperature changes were calculated by subtracting the initial temperature

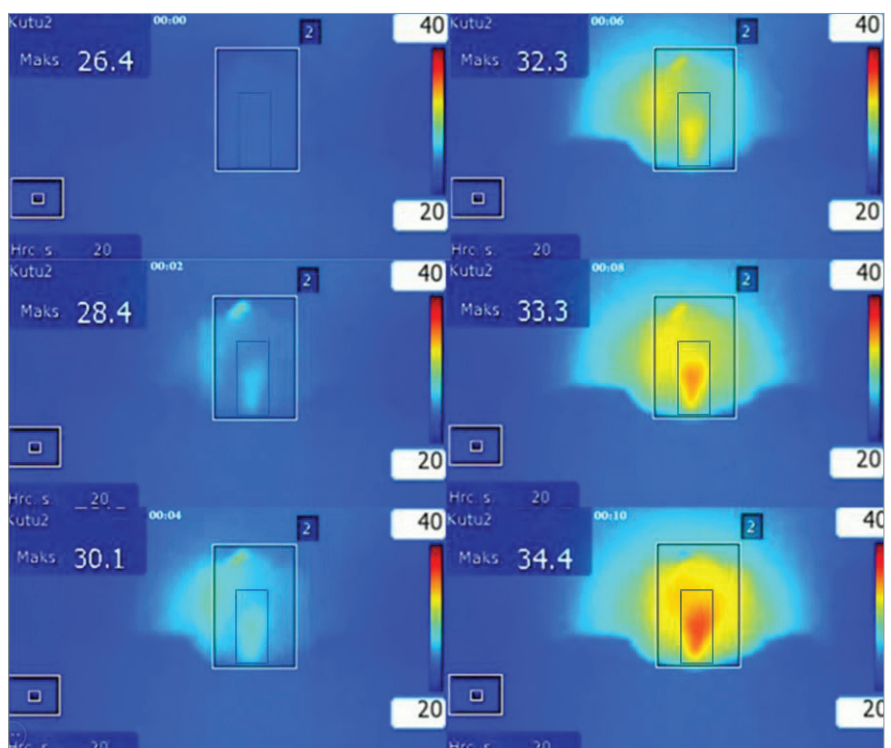

Figure 2. Thermal imaging of a sample tooth during polymerization. The temperature increased from $26.4^{\circ} \mathrm{C}$ to $34.4^{\circ} \mathrm{C}$

from the highest temperature value. An additional $5.5^{\circ} \mathrm{C}$ to the initial temperature degrees was accepted as the critical temperature threshold value. The time needed for cooling of the pulp chamber to the critical temperature threshold (critical cooling time) and to the initial temperature degree (cooling time) was also calculated.

\section{Statistical Analysis}

Data were analyzed using the Statistical Package for Social Science software (SPSS version 20.0, IBCM Corp.; Armonk, NY, USA). All parameters were found to be normally distributed after the Shapiro-Wilk test, and parametric tests were used for the temperature and time changes analyses. The mean and standard deviation of the temperature difference (TD), cooling time (CT), and critical cooling-time changes (CCT) were calculated. Temperature changes were assessed using a paired t-test. The analysis of variance (ANOVA) test and the Student-Newman-Keuls method were used for comparisons of all parameters between groups. A p $<0.05$ was considered statistically significant.

\section{Method Error}

All measurements were repeated for 10 samples of each group by the same investigator a month later. The reliability of measurements was calculated by the Cronbach alpha reliability test. Reliability coefficients were found to yield a sufficient reliability for both temperature (0.982-0.998) and time (0.919-0.956) measurements.

\section{RESULTS}

All photo-polymerization applications created significant temperature changes $(p<0.05)$. All LED groups showed greater temperature increases than the PAC groups. The highest temperature changes were observed in LED-SM with a 10-second exposure time $\left(6.66 \pm 1.98^{\circ} \mathrm{C}\right)$ and LED-EPM with a 6 -second exposure time $\left(6.50 \pm 1.64^{\circ} \mathrm{C}\right)$ among groups, while using PAC for 3 seconds created the lowest temperature rise $\left(1.81 \pm 0.99^{\circ} \mathrm{C}\right.$, Table 2$)$. 
Table 2. Comparison of initial and final temperature changes with different light-curing sources

\begin{tabular}{|c|c|c|c|c|c|c|c|}
\hline \multirow[b]{2}{*}{ Groups } & \multicolumn{2}{|c|}{ TO } & \multicolumn{2}{|c|}{ T1 } & \multicolumn{2}{|c|}{ T1-T0 } & \multirow[b]{2}{*}{$\mathbf{p}$} \\
\hline & Mean & SD & Mean & SD & Mean & SD & \\
\hline LED $10 \mathrm{~s}$ & 26.08 & 0.80 & 32.74 & 2.25 & 6.66 & 1.98 & $<0.05$ \\
\hline LED $6 \mathrm{~s}$ & 26.42 & 1.58 & 32.96 & 1.96 & 6.54 & 1.64 & $<0.05$ \\
\hline PAC $3 \mathrm{~s}$ & 26.65 & 1.12 & 28.46 & 2.11 & 1.81 & 0.99 & $<0.05$ \\
\hline
\end{tabular}

Table 3. Comparison of temperature difference, time changes, and critical time changes between groups

\begin{tabular}{|c|c|c|c|c|c|c|c|c|c|c|c|}
\hline \multirow[b]{2}{*}{ Groups } & \multicolumn{2}{|c|}{ LED $10 \mathrm{~s}$} & \multicolumn{2}{|c|}{ LED $3 \mathrm{~s}$} & \multicolumn{2}{|c|}{ LED $6 \mathrm{~s}$} & \multicolumn{2}{|c|}{ PAC $3 \mathrm{~s}$} & \multicolumn{2}{|c|}{ PAC $6 \mathrm{~s}$} & \multirow[b]{2}{*}{$\mathbf{p}$} \\
\hline & Mean & SD & Mean & SD & Mean & SD & Mean & SD & Mean & SD & \\
\hline TD & $6.66^{a}$ & 1.98 & $4.22^{\mathrm{b}}$ & 1.90 & $6.50^{\mathrm{a}}$ & 1.64 & $1.81^{c}$ & 0.99 & $4.78^{b}$ & 2.08 & $<0.05$ \\
\hline СCT & $28.67^{a}$ & 10.56 & - & - & $20.94^{\beta}$ & 11.46 & - & - & $18.67^{\beta}$ & 7.03 & $<0.05$ \\
\hline
\end{tabular}

LED-EPM with a 6-second exposure time (205.91 \pm 47.48 seconds) and LED-SM with a 10 seconds exposure time (196.80 \pm 77.19 seconds) displayed the longest CT to initial temperature, and parallel with the lowest temperature rise, the PAC group with 3 seconds of exposure time showed the shortest cooldown time (71.30 \pm 43.15 seconds) (Table 3 ).

Only 16 samples in Group I, 16 samples in Group III, and 6 samples in Group V exhibited a temperature rise of $\geq 5.5^{\circ} \mathrm{C}$. Therefore, the CCT comparison was performed only among the Groups I, III, and $V$, which used high-exposure times for curing (Table 3 ). In the LE-SM group with a 10-second curing time, it took the longest to return to the critical threshold value $(28.67 \pm 10.56$ seconds), followed by LED-EPM and PAC groups with 6-second curing times (20.94 \pm 11.46 and $18.67 \pm 7.03$ seconds, respectively).

\section{DISCUSSION}

The use of light-cured composites for orthodontic bracket bonding has increased in recent years. The QTH lights and HQTH have been widely used, but other technologies have come up with an even shorter irradiation duration (1). PAC and LED units are the most popular light resources nowadays, allowing for polymerization times as short as 3 seconds. Other advantages of LED lights compared to QTH, HQTH, and PAC lights are cordless, smaller, and lighter features; an increased lifetime; and no need for a noisy cooling fan (1). Although few studies exist in the literature about the thermal effects of curing lights on the pulp chamber during orthodontic bonding $(1,2,9)$, to the best of our knowledge, no data have been presented yet on the temperature changes in the pulp space during curing of orthodontic adhesives with high-energy light sources.

Beside the importance of clarification of the thermal side effects of high-energy light curing, the cooldown duration of the teeth is also important to protect the teeth from possible heat-related damages during the orthodontic bonding. Therefore, evaluation of the time-dependent temperature changes during different curing procedures would provide valuable information in terms of reducing the possible harmful effects of consecutive dental application on the same tooth by giving information about an appropriate waiting time. As the result of a literature review, there were no data regarding time-dependent temperature changes during different bonding procedures. Thus, the purpose of this study was to evaluate the time-dependent thermal effects of popular LED and PAC curing lights with high-energy outputs in the pulp chamber.

A standardized $250 \mathrm{cN}$ of force measured with an intraoral gage for 5 seconds was applied during the bracket placement to constitute a uniform adhesive thickness between the bracket base and the teeth in all samples. The effects of distance between the light-guiding tip and composite on the temperature rise were investigated, and a significant temperature decline was found when the distance of the light-guiding tip increased $(10,11)$. Therefore, the light-guiding tip was kept at the closest distance to brackets, not only to mimic the clinical conditions during bracket bonding, but also to measure the maximum heat changes transferred from the bracket surface to the pulpal site of the dentin effectively.

To the best of our knowledge, no accurate data exist in the literature that evaluated the possible harmful effects of heat-generating dental procedures on the tolerance limits of the human pulp tissue, so the maximum temperature without irreversible damage on the human pulp tissues is still unknown (12). Many studies have used the results by Zach and Cohen (7), derived from primate teeth as threshold values due to lack of such data. Zach and Cohen (7) investigated detrimental effects of heat on pulp tissues of primates and reported that a $5.5^{\circ} \mathrm{C}$ tempera- 
ture increase in the pulp caused irreversible damage in 15\% of macaque rhesus monkeys, an $11^{\circ} \mathrm{C}$ temperature increase led to irreversible alterations in the pulp of $60 \%$ of animals, and a $16.5^{\circ} \mathrm{C}$ temperature increase resulted in an irreversible necrotic response of the pulp tissue for all animals. Thus, a $5.5^{\circ} \mathrm{C}$ temperature rise in the pulp chamber has been accepted as a threshold value in terms of beginning of the pulp damage, in our study. Two groups, LED-SM with a 10-second exposure time and LEDEPM with a 6-second exposure time exceeded the critical $5.5^{\circ} \mathrm{C}$ threshold value, while 3 seconds of the LED-EPM application resulted in a $4.22 \pm 1.90^{\circ} \mathrm{C}$ temperature rise. However, both PAC groups did not exceed the critical value for pulpal injury. The PAC group with a 3-second exposure time showed the least temperature rise among the study groups, while using 6 seconds of PAC light increased the temperature for $4.78 \pm 2.08^{\circ} \mathrm{C}$.

The individual recovery capacity of the pulp is another important factor for the level of thermal injury (12). Kraut et al. (13) histologically found no pulpal inflammation or necrosis 2 weeks after debonding the ceramic brackets electrothermally, while Jost-Brinkmann et al. (14) showed a localized pulpal damage in several teeth with histological investigation of the human pulp in vivo, where more than one heating cycle was achieved following thermal debonding of ceramic brackets. The reduced recovery capacity of the pulp tissues due to depressed pulpal respiration after orthodontic force application was also reported (12, $15,16)$. So, a temperature rise after orthodontic bonding with curing lights can threaten the vitality of the pulpal tissues (12).

Two factors are important for the temperature increment during polymerization of resin composites with light activation: absorbed energy as a result of irradiation and exothermic polymerization process (1). Thus, increased irradiation due to high-energy output lights was considered a risk factor for pulpal damage $(1,2,17,18)$. Hannig and Bott (5) investigated the temperature changes of pulp chamber in a Class II restorative cavity in a molar tooth, leaving a dentin layer $1 \mathrm{~mm}$ in thickness between the pulp chamber and the proximal cavity wall, and they found a greater temperature increase in curing units with a high-energy output (PAC) than in conventional or lower energy output lights. On the other hand, the importance of the exposure time rather than a high-energy output has also been presented in the orthodontic literature $(1,2,9)$. The contrary findings between restorative and orthodontic studies evaluating the heat changes during light curing can be attributed to the differences in orthodontic and restorative bonding. In orthodontic bonding, brackets are placed onto the enamel without any connection to the dentine, but in restorative dentistry, the resins are commonly applied to dentine with a thin layer to pulpal tissues, and heat can be transferred to the pulpal area more easily (9). In addition, in restorative procedures, light energy is applied directly on the composite, and it can reach the required energy level rapidly in the resin region because it does not encounter an obstacle such as bracket. However, during orthodontic bonding, the bracket thickness must be passed by the light photons to reach to the resin. While some of the light energy is absorbed by the metal through the bracket thickness, the duration of curing may be getting importance to have enough energy accumulation for polymerization in the resin zone.
None of the previous orthodontic bonding studies, except a HQTH group $\left(6.85 \pm 2.44^{\circ} \mathrm{C}\right)$ with 40 seconds of curing time in the study by Malkoç et al. (1), showed a temperature rise exceeding the critical value of $5.5^{\circ} \mathrm{C}$. The studies showing the thermal changes during orthodontic bonding with LED lights used the power intensity values $400-1100 \mathrm{~mW} / \mathrm{cm}^{2}$ and PAC lights 1200 $1850 \mathrm{~mW} / \mathrm{cm}^{2}(1,2,9)$. The power intensity values of the LED groups of this study $\left(1000-3200 \mathrm{~mW} / \mathrm{cm}^{2}\right)$ were higher than in previous studies in the literature, and the energy outputs of our PAC groups (1200-1500 $\left.\mathrm{mW} / \mathrm{cm}^{2}\right)$ were similar to other studies. Therefore, higher temperature changes were an expected result of higher energy output. The highest temperature rise (mean, $6.66 \pm 1.98{ }^{\circ} \mathrm{C}$ ) was found in the LED group with 10 seconds of irradiation time in our study. Moreover, LED-EPM group with 3 seconds of exposure time and $3200 \mathrm{~mW} / \mathrm{cm}^{2}$ power intensity value showed $4.22 \pm 1.90^{\circ} \mathrm{C}$ temperature rise, but when the exposure time increased to 6 seconds, the $5.5^{\circ} \mathrm{C}$ of critical value was exceeded. Similar finding was also observed for the PAC groups: the exposure time and temperature rise showed a positive correlation, but no PAC group exceeded $5.5^{\circ} \mathrm{C}$. On the other hand, Uzel et al. (2) found a significantly higher temperature increase when the tip of the light unit positioned at the surface of the teeth was more distant than $10 \mathrm{~mm}$, and it showed higher heat changes in mandibular incisors than the premolar teeth. So, modifications of the light-guide tip distance and preference of short exposure duration during light curing on teeth that have thin enamel and dentin just like mandibular incisors may provide a smaller temperature increase in pulpal tissues.

The results of the literature review showed that there were no data regarding the cooling of teeth after orthodontic bonding. $\mathrm{CT}$ findings of our study revealed parallel findings with the exposure time-heating of the pulp chamber relationship. When the exposure time increased, CT and CCT also increased. Nearly 3 minutes were needed to cool down the initial temperature values in groups with an increased CT. Cummings et al. (12) showed a $16.2^{\circ} \mathrm{C}$ temperature increase on the pulpal wall during the debonding of ceramic brackets and found that the temperature returned to normal values within 2-3 minutes. So, the authors recommended waiting for 5 minutes of the cooling period before the next heating application (12). The LED-SM group with a 10-second exposure time showed the highest CCT time (28.67 \pm 10.56 seconds), continued by 6 seconds of the LED-EPM and PAC groups $(20.94 \pm 11.46$ and $18.67 \pm 7.03$ seconds, respectively). These results also showed that there was a relationship between the temperature change and CT. This outcome indicates not only the importance of curing time during the orthodontic bracket bonding (19), but also to achieve the light curing of teeth, without irradiating the neighboring teeth during bonding to give enough time to cooldown. The time-dependent temperature change results of this study may be also beneficial to establish a time-related bonding protocol.

As a limitation of our study, in vitro conditions cannot ideally reflect the in vivo environment. A lot of factors such as blood circulation of the pulp chamber, fluid flow of dentin tubules, age of the patient, periodontal tissues, and saliva can change or reduce the heat transfer to the pulpal area and CT of teeth $(1,9,20)$. But 
histological human studies are needed both for evaluating the exact effects of heat changes to pulpal tissues and for determining the thermal thresholds of the human pulp.

\section{CONCLUSION}

- LED lights with an increased exposure time induced significant temperature rises, and they exceeded $5.5^{\circ} \mathrm{C}$ of the critical threshold value on the pulpal wall, while the critical threshold value was not exceeded in any of the PAC light groups.

- An increased exposure time during orthodontic bonding also increased the $\mathrm{CT}$ of the pulpal wall to both initial and critical threshold temperature values.

- Although no data exist with regard to thermal effects of curing lights on human pulpal tissues, the clinicians should be careful during the orthodontic bonding using curing lights that have increased exposure times, because of a decreased recovery capacity of pulpal tissues due to the orthodontic force.

Ethics Committee Approval: Ethics committee approval was received for this study from the Clinical Research Ethics Committee of Erciyes University (Approval Date: October 13, 2017; Decision No: 2017/472).

Informed Consent: Written informed consent was obtained from the patients or their legal guardians.

Author Contributions: Concept - G.K., O.E., N.G.A., G.C., V.A.; Design G.K., O.E., N.G.A., G.C., V.A.; Supervision - G.K., O.E.; Resources - N.G.A., G.K., O.E., G.C., V.A.; Materials - N.G.A., G.C; Data Collection and/or Processing - N.G.A., G.C.; Analysis and /or Interpretation - N.G.A., G.K.; Literature Search -N.G.A.; Writing Manuscript - N.G.A., G.K.; Critical Reviews - G.K.

Conflict of Interest: The authors have no conflict of interest to declare.

Financial Disclosure: The authors declared that this study has received no financial support.

\section{REFERENCES}

1. Malkoc S, Uysal T, Usumez S, Isman E, Baysal A. In-vitro assessment of temperature rise in the pulp during orthodontic bonding. Am J Orthod Dentofacial Orthop 2010; 137: 379-83. [CrossRef]

2. Uzel A, Buyukyilmaz T, Kayalioglu M, Uzel I. Temperature rise during orthodontic bonding with various light-curing units - an in vitro study. Angle Orthod 2006; 76: 330-4.

3. Lindberg A, Peutzfeldt A, Van Dijken JW. Effect of power density of curing unit, exposure duration, and light guide distance on composite depth of cure. Clin Oral Investig 2005; 9: 71-6. [CrossRef]
4. Goodis HE, White JM, Andrews J, Watanabe LG. Measurement of temperature generated by visible-light cure lamps in an in vitro model. Dent Mater 1989; 5: 230-4. [CrossRef]

5. Hannig M, Bott B. In-vitro pulp chamber temperature rise during composite resin polymerization with various light-curing sources. Dent Mater 1999; 15: 275-81. [CrossRef]

6. Tarle Z, Meniga A, Knezevic A, Sutalo J, Ristic M, Pichler G. Composite conversion and temperature rise using a conventional, plasma arc and experimental blue LED curing unit. J Oral Rehabil 2002; 29: 662-7. [CrossRef]

7. Zach L, Cohen G. Pulp response to externally applied heat. Oral Surg Oral Med Oral Pathol 1965; 19: 515-30. [CrossRef]

8. Buchalla W, Attin T. External bleaching therapy with activation by heat, light or laser-a systematic review. Dent Mater 2007; 23: 58696. [CrossRef]

9. Ulusoy C, Irmak O, Bagis YH, Ulusoy OI. Temperature rise and shear bond strength of bondable buccal tubes bonded by various light sources. Eur J Orthod 2008; 30: 413-7. [CrossRef]

10. Cacciafesta V, Sfondrini MF, Barina E, Scribante A, Garino F, Klersy C. Effect of different light sources and guides on shear bond strength of brackets bonded with 2 adhesive systems. Am J Orthod Dentofacial Orthop 2005; 128: 99-102. [CrossRef]

11. Price RB, Ehrnford L, Andreou P, Felix CA. Comparison of quartz-tungsten-halogen, light-emitting diode, and plasma arc curing lights. J Adhes Dent 2003; 5: 193-207.

12. Cummings M, Biagioni P, Lamey PJ, Burden DJ. Thermal image analysis of electrothermal debonding of ceramic brackets: an in vitro study. Eur J Orthod 1999; 21: 111-8. [CrossRef]

13. Kraut J, Radin S, Trowbridge HI, Emling RC, Yankell SL. Clinical evaluations on thermal versus mechanical debonding of ceramic brackets. J Clin Dent 1991; 2: 92-6.

14. Jost-Brinkmann PG, Stein H, Miethke RR, Nakata M. Histological investigations of human pulp after thermo-debonding of metal and ceramic brackets. Am J Orthod Dentofacial Orthop 1992; 102: 4107. [CrossRef]

15. Hamersky PA, Weiner AD, Taintor JF. The effect of force application on the pulpal tissue respiration rate in the human premolar. Am J Orthod 1980; 77: 368-78. [CrossRef]

16. Unsterseher RE, Nieberg LG, Weimer AD, Dyer JK. The response of human pulpal tissue after orthodontic force application. Am J Orthod Dentofacial Orthop 1987; 92: 220-4. [CrossRef]

17. Ozturk B, Ozturk AN, Usumez A, Usumez S, Ozer F. Temperature rise during adhesive and resin composite polymerization with various light curing sources. Oper Dent 2004; 29: 325-32.

18. Usumez A, Ozturk N. Temperature increase during resin cement polymerization under a ceramic restoration: effect of type of curing unit. Int J Prosthodont 2004; 17: 200-4. [CrossRef]

19. Bagis B, Bagis Y, Ertas E, Ustaomer S. Comparison of the heat generation of light curing units. J Contemp Dent Pract 2008; 9: 65-72.

20. Runnacles P, Arrais CAG, Pochapski MT, Dos Santos FA, Coelho U, Gomes JC, et al. In vivo temperature rise in anesthetized human pulp during exposure to a polywave LED light curing unit. Dent Mater 2015; 31: 505-13. [CrossRef] 